\title{
Effect of Different Cooling Regimes on the Mechanical Properties of Cementitious Composites Subjected to High Temperatures
}

\author{
Jiangtao Yu, Wenfang Weng, and Kequan Yu \\ College of Civil Engineering, Tongji University, Shanghai 200092, China \\ Correspondence should be addressed to Kequan Yu; zjzjykq@163.com
}

Received 19 January 2014; Accepted 27 March 2014; Published 9 April 2014

Academic Editors: J. Kinuthia and U. C. Melo

Copyright (C) 2014 Jiangtao Yu et al. This is an open access article distributed under the Creative Commons Attribution License, which permits unrestricted use, distribution, and reproduction in any medium, provided the original work is properly cited.

\begin{abstract}
The influence of different cooling regimes (quenching in water and cooling in air) on the residual mechanical properties of engineered cementitious composite (ECC) subjected to high temperature up to $800^{\circ} \mathrm{C}$ was discussed in this paper. The ECC specimens are exposed to $100,200,400,600$, and $800^{\circ} \mathrm{C}$ with the unheated specimens for reference. Different cooling regimens had a significant influence on the mechanical properties of postfire ECC specimens. The microstructural characterization was examined before and after exposure to fire deterioration by using scanning electron microscopy (SEM). Results from the microtest well explained the mechanical properties variation of postfire specimens.
\end{abstract}

\section{Introduction}

Concrete is the most widely used construction material in the world. Although it was primarily designed for carrying compressive loads, concrete in real field conditions is also subjected to tensile stresses because of structural loading, shrinkage (if the shrinkage is restrained), chemical attack, and thermal deformations. The tensile strength of concrete is only approximately $10 \%$ of its compressive strength and brittle concrete cracks when subjected to tensile stresses. In recent years, the effort to modify the brittle nature of ordinary concrete has resulted in modern concepts of ultrahigh performance fiber-reinforced cementitious composites (UHP-FRCC), which are characterized by tensile strainhardening after first cracking. Depending on its composition, its tensile strain capacity can be up to several hundred times of those normal and fiber-reinforced concrete. The engineered cementitious composite (ECC) is a special type of UHPFRCC designed based on micromechanical principles to strain-harden in tension. It offers high ductility under uniaxial tensile loading and improved durability due to an intrinsically tight crack width of less than $100 \mu \mathrm{m}[1,2]$. During the last decade, the use of ECC has considerably grown up, and it was used in a variety of structures in various regions $[3,4]$.
It is well accepted that, in ECC mixture, partial Portland cement would be replaced by pozzolanic materials, particularly fly ash. For normal concrete, the partial replacement of Portland cement with pozzolanic materials, generally from $5 \%$ to $30 \%$ by mass, has been shown to improve the durability properties of blended cements [5-7]. This is largely attributed to the pozzolanic reaction, where reactive siliceous and aluminous phases react with portlandite to form new C$\mathrm{S}-\mathrm{H}$ or $\mathrm{C}-\mathrm{AS}-\mathrm{H}$ type phases. Importantly, the replacement of Portland cement with pozzolans reduces the overall $\mathrm{CO}_{2}$ footprint of the material. Emissions of $\mathrm{CO}_{2}$ are an important consideration in cement production since, due to its sheer scale, the industry accounts for $5-8 \%$ of global anthropogenic emissions [8].

Significant attention has been brought to the study of its rheological, mechanical, and durability related properties of ECC. With an increase in the application of ECC, the risk of exposure to elevated temperatures increases as well. The behavior of ECC exposed to high temperature has to be evaluated in particular.

For normal cement based composite, high temperatures caused physical and chemical changes, resulting in its mechanical property deterioration, such as compressive strength and modulus of elasticity. The residual properties of 
ECC after exposure to high temperatures have been studied by several researchers, mainly on the heating temperatures, mineral admixtures of fly ash, and fiber influence $[9,10]$. But there are still some aspects that remained to be studied. For normal cement composite, different cooling regimes, that is, cooling in air, quenching in water, or water spraying, had a significant influence on the residual mechanical properties of postfire composite $[11,12]$. The main objective of this research is to gain a better understanding of the influence of cooling regimes on the postfire ECC specimens subjected to high temperature up to $800^{\circ} \mathrm{C}$.

\section{Experimental Studies}

2.1. Materials, Mix Proportions, and Basic Mechanical Properties. The materials used in the production of ECC mixture were Type I Portland cement (C), class F fly ash (FA), sand, water, polyvinyl alcohol (PVA) fibers, a polycarboxylic ether type high-range water-reducing admixture (HRWR), and Hydroxypropylmethyl cellose (HPMC). The mix details are given in Table 1. Unlike typical fiber-reinforced cementitious composites, the component characteristics and proportions within the ECC are carefully determined with the use of micromechanical design tools to achieve the desired strainhardening response [13]. In this ECC mixture, about $30 \%$ of Portland cement was replaced by fly ash, which made it a kind of eco-friendly cementitious materials.

The PVA fibers with a diameter of $39 \mu \mathrm{m}$ and a length of $8 \mathrm{~mm}$ are purposely manufactured with a tensile strength $(1620 \mathrm{MPa})$, elastic modulus (42.8 GPa), and maximum elongation $(6.0 \%)$ matching those needed for strain-hardening performance. Additionally, the surface of the PVA fibers is coated with a proprietary oiling agent $1.2 \%$ by mass to tailor the interfacial properties between fiber and matrix for strainhardening performance [13].

To characterize the direct tensile behavior of the ECC mixtures, the dog-bone specimens were used. Direct tensile tests were conducted under displacement control at a loading rate of $0.005 \mathrm{~mm} / \mathrm{s}$. The typical tensile stress-strain curves of the ECC mixtures at 28 days are shown in Figure 1. As shown in Table 1, the ECC composites exhibited a strain capacity of $3.5 \%$ at 28 days, with an ultimate strength of about $3.3 \mathrm{MPa}$.

2.2. Test Specimen Preparation and Testing Procedure. Specimens were removed from the molds at 1 day and kept in a water tank until the age of 28 days. Five specimens were tested under compression immediately after conditioning; these control specimens will be referred to as those tested after exposure to normal curing condition (unheated).

Computer controlled furnace was used for the heating of specimens with constant heating rate of about $13.3^{\circ} \mathrm{C} / \mathrm{min}$ to reach the prescribed $100,200,400,600$, and $800^{\circ} \mathrm{C}$ temperature levels. The temperature was measured in the air at a position above the specimen inside the furnace. The temperature was maintained constant for an hour to achieve the thermal steady state condition after the target temperature is reached. It was expected that because of small size of specimens used in this study, the temperature in the center of the specimen
TABLE 1: Mixture properties of ECC.

\begin{tabular}{lc}
\hline & ECC \\
\hline Cement $(\mathrm{C})\left(\mathrm{kg} / \mathrm{m}^{3}\right)$ & 650 \\
Fly ash $(\mathrm{FA})\left(\mathrm{kg} / \mathrm{m}^{3}\right)$ & 325 \\
Water $(\mathrm{W})\left(\mathrm{kg} / \mathrm{m}^{3}\right)$ & 375 \\
PVA fiber $\left(\mathrm{kg} / \mathrm{m}^{3}\right)$ & 26 \\
Sand $\left(\mathrm{kg} / \mathrm{m}^{3}\right)$ & 480 \\
HRWR $\left(\mathrm{kg} / \mathrm{m}^{3}\right)$ & 12 \\
HPMC $\left(\mathrm{kg} / \mathrm{m}^{3}\right)$ & 1.90 \\
W/(C $+\mathrm{FA})$ & 0.38 \\
FA/C & $50 \%$ \\
28-day tensile strain $(\%)$ & 3.5 \\
28-day tensile strength $(\mathrm{MPa})$ & 3.3 \\
\hline
\end{tabular}

TABLE 2: Two cooling regimes for different curing-age ECC specimens.

\begin{tabular}{lcc}
\hline Temperature & $\begin{array}{c}\text { Cooling at room } \\
\text { temperature }\end{array}$ & Quenching in water \\
\hline 100 & $\checkmark$ & None \\
$200^{\circ} \mathrm{C}$ & $\checkmark$ & None \\
$400^{\circ} \mathrm{C}$ & $\checkmark$ & $\checkmark$ \\
$600^{\circ} \mathrm{C}$ & $\checkmark$ & None \\
$800^{\circ} \mathrm{C}$ & $\checkmark$ & $\checkmark$ \\
\hline
\end{tabular}

reached the target temperature during the one-hour stabilization phase. The heating regime is shown in Figure 2. After heating, the samples were subjected to two cooling regimes as given in Table 2. After cooling, the specimens were sealed for 7 days before the compressive test. The test was performed under displacement control at a loading rate of $0.005 \mathrm{~mm} / \mathrm{s}$ on a closed-loop controlled material testing system with $200 \mathrm{kN}$ capacity. During the compressive tests, the load and the deflection values (obtained from a pair of LVDT's attached to the test set-up) were recorded on a computerized data acquisition system. Four samples were tested for each heating temperature and cooling regime. The weight of each specimen was also measured before and after exposure to calculate the mass loss of fire-deteriorated specimens.

The specimens are named as follows: temperature-cooling regime. For example, $400 R(W)$, here $R$ means cooling in air and $W$ means cooling in water for 5 minutes.

\section{Experimental Results and Discussions}

3.1. Surface and Internal Characteristics. It is observed that when the ECC specimens were exposed to high temperatures, some changes in color occurred. Figure 3 shows that the color of ECC specimens changed from gray at $20^{\circ} \mathrm{C}$ to buff at $800^{\circ} \mathrm{C}$ due to the loss of water and chemical decomposition. The color of the specimens subjected to $800^{\circ} \mathrm{C}$ and then quenching in water turned to dark gray which may be due to further hydration of the composite.

Surface crack patterns of ECC specimens due to the high temperature exposure were almost same up to $800^{\circ} \mathrm{C}$. 


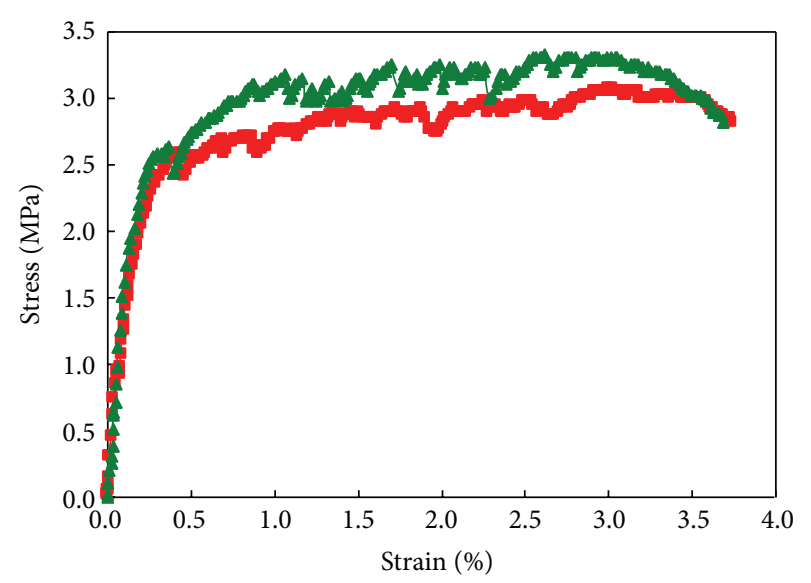

FIgURE 1: Typical tensile stress-strain response of ECC at 28 days.

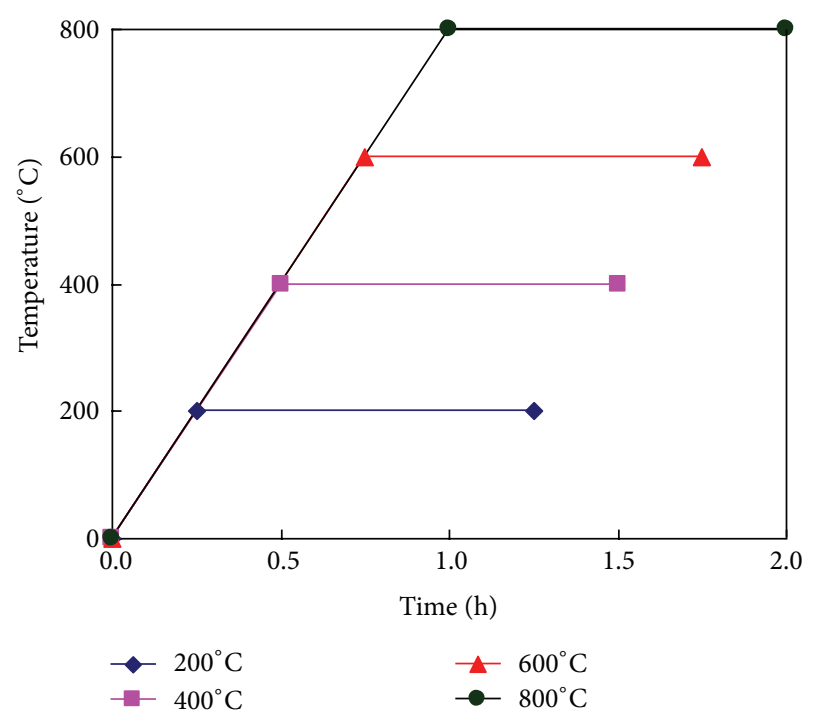

FIGURE 2: Heating regime for ECC specimens.

Cracks became apparent after $400^{\circ} \mathrm{C}$, and hairline cracks were monitored above $400^{\circ} \mathrm{C}$. Increasing the exposure temperature to $800^{\circ} \mathrm{C}$ increased the size of microcracking as being consistent with pore structure variation of the specimens $[9,10]$. However, quenching in the water helped to heal the surface crack due to further hydration.

3.2. Mass Loss and Water Absorption. The deterioration of specimens subjected to various elevated temperatures was also assessed by mass loss measurements. Figure 4 shows the relation between mass loss $\left(M_{i} / M_{0}\right)$ (in percentage) and temperature of heat-exposed ECC. $M_{i}$ is the mass after specific thermal heat exposure, and $M_{0}$ is initial mass, prior to heat exposure. As seen in Figure 4, the mass loss increased with the increasing temperature of thermal exposure, a result mainly associated with the liberation of free and physically bound water. At higher temperatures of 600 and $800^{\circ} \mathrm{C}$, the weight change of ECC was caused by the dehydration of paste [14]. During a heat treatment up to $400^{\circ} \mathrm{C}$, the weight of the melted fibers also had an influence on mass loss.

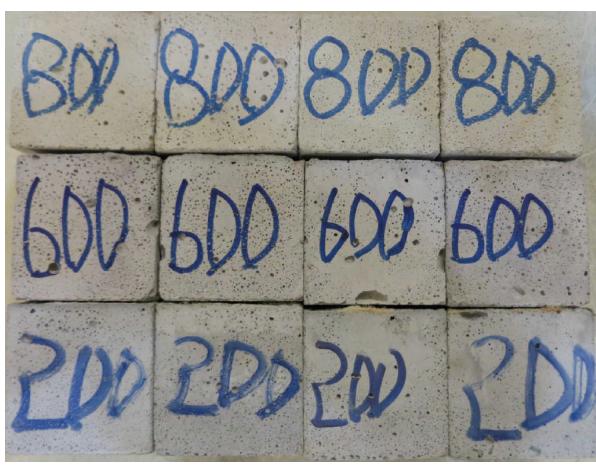

FIGURE 3: Color changes and surface cracks of postfire specimens.

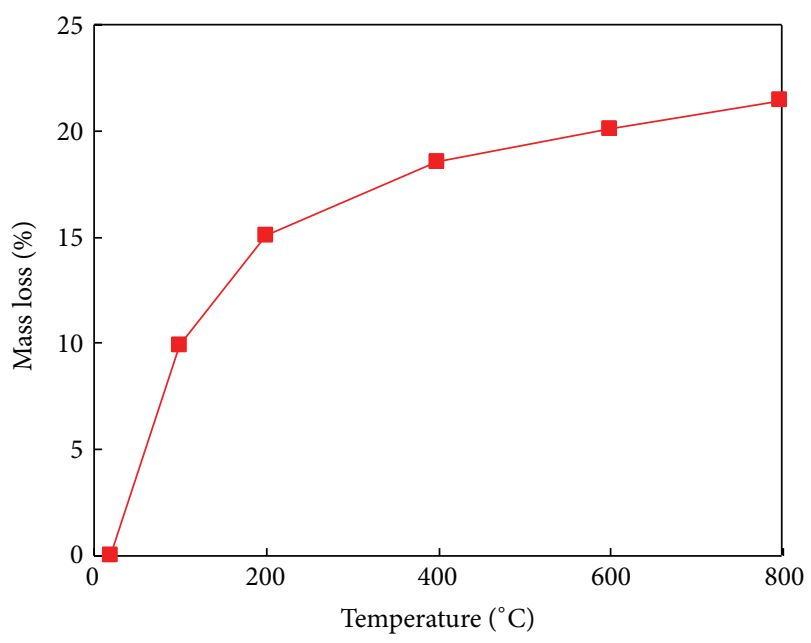

FIGURE 4: Mass loss of specimens of all curing ages with temperatures.

For the specimens quenching in water, the water absorption was determined by weighting the mass variation before and after quenching. The water absorption rates were $9.96 \%$ and $24.14 \%$ for the specimens of $400 \mathrm{~W}$ and $800 \mathrm{~W}$, respectively.

3.3. Microstructure Characterization by Using SEM Observations. To study the behavior of fibers and matrix microstructure after various elevated temperatures, observations with an SEM were performed on samples taken from the core of postfire ECC specimens that had been exposed to temperature between 200 and $800^{\circ} \mathrm{C}$ for one hour. The specimens that had been quenched in the water for 5 minutes were also observed. Figure 5 shows the SEM micrographs of various postfire ECC specimens exposed to different heating temperatures and cooling regimens. Figures 5(a) and 5(b) show the SEM micrographs of ECC specimens subjected to $200^{\circ} \mathrm{C}$ and $400^{\circ} \mathrm{C}$ cooling in air. The fiber did not melt when the specimens are subjected to $200^{\circ} \mathrm{C}$. After exposure to $400^{\circ} \mathrm{C}$, PVA fibers melt completely, creating additional interconnected pores and small channels in the matrix that fibers alone constitute a connected network. Therefore, the use of PVA fiber clearly affects porosity at high temperatures. 


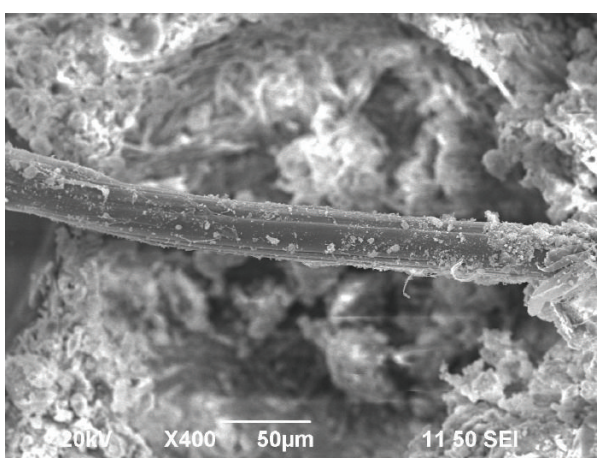

(a) $200 R$

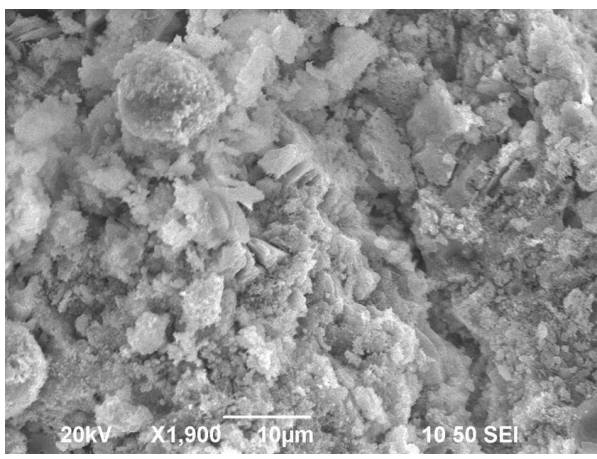

(c) $800 R$

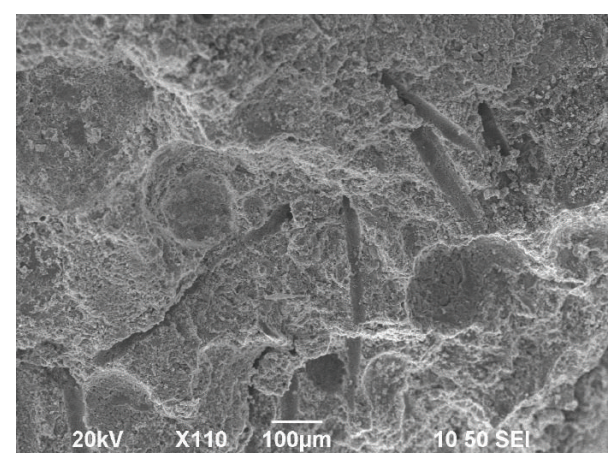

(b) $400 R$

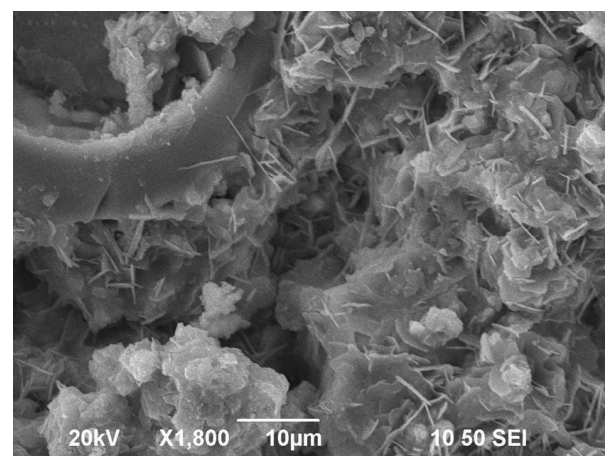

(d) $800 \mathrm{~W}$

FIGURE 5: SEM micrograph of ECC specimens subjected to different heating temperatures and cooling regimes: (a) 200R; (b) 400R; (c) 800R; (d) $800 \mathrm{~W}$.

After exposure to $400^{\circ} \mathrm{C}$, the number and width of microcracks increase obviously compared to specimens subjected to $200^{\circ} \mathrm{C}$ from the SEM observation. Figures 5(c) and 5(d) show the micrographs of ECC specimens for $800 R$ and $800 \mathrm{~W}$. After exposure to $800^{\circ} \mathrm{C}$, the morphology of hydration products shows numerous microcracks and massive structure of hydration products; the hydration products are appearing as ill crystallized or amorphous structures by losing the characteristic crystal structure. However, Figure 5(d) shows the typical crystal structure of specimens quenching in water and curing for 7 days. The produce of new crystal enhances the strength of specimens which would be discussed in following section. Additionally, from the SEM observation, it is found that there is more new generated crystal in $800 \mathrm{~W}$ specimens than in $400 \mathrm{~W}$ specimens, which results in more significant mechanical increases in $800 \mathrm{~W}$ specimens.

3.4. Residual Compressive Strength and Stress-Strain Curves. Figure 6 shows the influence of temperature on the compressive strength and stiffness of postfire ECC specimens. Each point in Figure 6 was obtained from the average of at least four test specimens. The coefficient of variance (COV) values for the compressive strength values ranged from $2.7 \%$ to $10.4 \%$. The narrow range of COV values is an indication of the consistent repeatability of the compressive strength test method even for fire-deteriorated specimens.

As expected, exposure to high temperatures influenced the residual compressive strength of ECC specimens substantially. Percent variation in compressive strength can be classified in two distinct patterns of strength loss, $23-200^{\circ} \mathrm{C}$ and $200-800^{\circ} \mathrm{C}$. Temperatures no more than $200^{\circ} \mathrm{C}$ seem to help the strength increase. Mean compressive strength of 28-day ECC specimens increase by $32 \%$ after exposure to $200^{\circ} \mathrm{C}$. It can be partially due to the strengthened cement paste during the evaporation of free water, which leads to greater Van der Waal's forces as a result of the cement gel layers moving closer to each other $[15,16]$. Further hydration of cementitious materials is another important cause of the hardening of cement paste. Especially for FA composite, unhydrated PFA particles can reacted with calcium hydroxide and gels produced $\mathrm{C}-\mathrm{S}-\mathrm{H}$ like $[14,16]$. Although high temperature induced more microcracks, the enhancement effect mentioned above totally overcame the damage caused by microcracks.

Beyond $200^{\circ} \mathrm{C}$, the compressive strength decreases monotonously. However, the influence of high temperature exposure on the residual compressive strength is not prominent up to $400^{\circ} \mathrm{C}$ with the mean compressive strength still being increased by $6 \%$ after exposure to $400^{\circ} \mathrm{C}$ with the same reasons as mentioned before. This might be due to the less sensitivity of compressive strength to minor microcracks. Heating up to $400^{\circ} \mathrm{C}$ generated a relatively small amount of cracking, which did not cause any immediate loss of carrying capacity in compression because the slightly cracked concrete could work as a highly redundant structure [17]. Beyond $400^{\circ} \mathrm{C}$, however, compressive strength 
dropped monotonously by $32 \%$ and $61 \%$ at $600^{\circ} \mathrm{C}$ and $800^{\circ} \mathrm{C}$, respectively. According to the variation of the residual compressive strength, temperature of $600^{\circ} \mathrm{C}$ and above might be regarded as critical temperature range for the strength loss of ECC. When the temperature was raised to $600^{\circ} \mathrm{C}$, decomposition of the major hydrate, known as tobermorite (gel), was inevitable [18], causing severe increase in the microstructure of its matrix and the loss of binder property. By comparing the data given in this paper with published work on normal concrete or fiber-reinforced concrete $[15,19-21]$ that the standard ECC mixture (by retaining more than $35 \%$ of its original compressive strength and $22 \%$ of its original stifness capacity ater exposure to peak temperatures of $800^{\circ} \mathrm{C}$ for 1 hour) performs similarly to or better than fire-damaged plain concrete with steel and/or polypropylene fibers exposed to similar elevated temperatures.

The present test results are in line with the findings of previous studies $[9,10]$. The compressive strength variation with temperatures could be expressed by the following equations:

$$
\begin{array}{r}
f_{c}=0.0017 T_{m}+0.9847, \quad 20^{\circ} \mathrm{C} \leq T_{m} \leq 200^{\circ} \mathrm{C} \\
R^{2}=0.9638 \\
f_{c}=-0.0016 T_{m}+1.6542, \quad 200^{\circ} \mathrm{C} \leq T_{m} \leq 800^{\circ} \mathrm{C} \\
R^{2}=0.9947 .
\end{array}
$$

From Figure 6, it can be seen that the stiffness of postfire specimens shares a similar but more sensitive tendency $[19,20]$ with exposure temperatures, which also could be classified in two stages. The mean compressive stiffness of ECC specimens increased by $12 \%$ after exposure to $200^{\circ} \mathrm{C}$, while it decreased by $20 \%, 58 \%$, and $73 \%$ after exposure to 400,600 , and $800^{\circ} \mathrm{C}$. The compressive stiffness variation with temperatures could be expressed by the following equations:

$$
\begin{array}{r}
f_{c}=0.0007 T_{m}+0.9867, \quad 20^{\circ} \mathrm{C} \leq T_{m} \leq 200^{\circ} \mathrm{C}, \\
R^{2}=1, \\
f_{c}=-0.0015 T_{m}+1.3907, \quad 200^{\circ} \mathrm{C} \leq T_{m} \leq 800^{\circ} \mathrm{C}, \\
R^{2}=0.9947 .
\end{array}
$$

Additionally, the displacement corresponding to the peak load increases with temperatures, which could be expressed by

$$
\begin{array}{r}
f_{c}=0.0007 T_{m}+1.04, \quad 20^{\circ} \mathrm{C} \leq T_{m} \leq 800^{\circ} \mathrm{C}, \\
R^{2}=0.953 .
\end{array}
$$

Figure 7 shows the relationships between the mass loss and the mechanical properties, including the compressive strength and stiffness. It can be seen that the mechanical properties increased up to the mass loss around 15\%, corresponding to the heating temperature of $200^{\circ} \mathrm{C}$. Afterwards, the mechanical properties decreased with the increasing mass loss. The stifness is more sensitive than strength to mass loss or heating temperature.

Figure 8 shows the influence of cooling regimes on the residual mechanical properties. For the specimens subjected

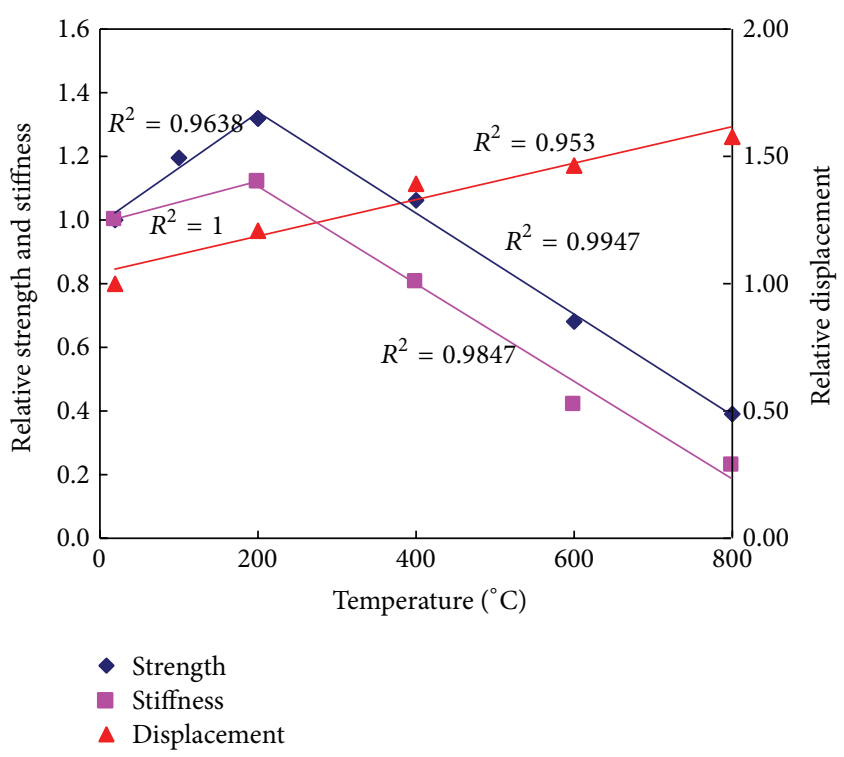

FIGURE 6: Compressive strength, stiffness, and displacement corresponding to the peak load with temperatures.

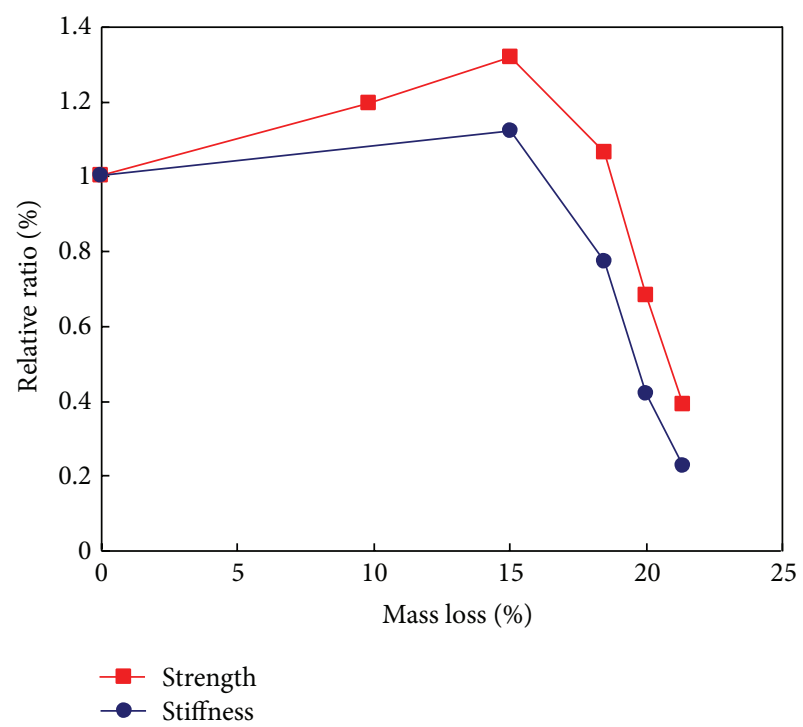

FIGURE 7: Relationships of strength and stiffness to mass loss.

to heating temperature of $400^{\circ} \mathrm{C}$, the compressive strength and stiffness of specimens quenching in water decreased by $15 \%$ and $6 \%$ compared to the ones cooling in air, while, for $800^{\circ} \mathrm{C}$, the compressive strength and stiffness of specimens quenching in water were 1.86 and 2.65 times to the ones cooling in air. As mentioned in Section 3.3, there is more new generated crystal in $800 \mathrm{~W}$ specimens than in $400 \mathrm{~W}$ specimens, which results in a more significant mechanical increase in $800 \mathrm{~W}$ specimens. Meanwhile the displacement corresponding to the peak load of $400 \mathrm{~W}$ and $800 \mathrm{~W}$ deceased by $11 \%$ and $21 \%$ compared with the specimens cooling in air.

The stress-strain curves of ECC specimens at room temperature and elevated temperatures are compared in 


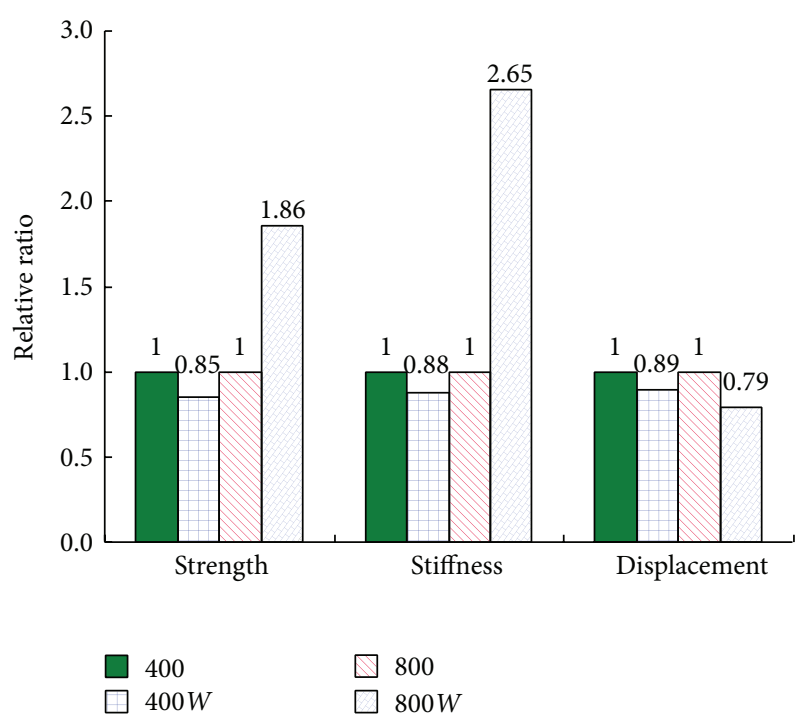

FIGURE 8: Influence of cooling regimes on compressive strength, stiffness, and displacement corresponding to peak load.

Figure 9. For temperature no more than $200^{\circ} \mathrm{C}$, ultimate stress increased with the increasing temperature, particularly for heating temperatures of $200^{\circ} \mathrm{C}$. For temperatures beyond $200^{\circ} \mathrm{C}$, ultimate stress decreased with the increasing temperatures; however, the stress for $400^{\circ} \mathrm{C}$ was still a little higher than the one of unheated specimens. The slope decreased with the increase in exposure temperature up to $800^{\circ} \mathrm{C}$, indicating a reduction in the stiffness of the ECC. The reduction in ECC stiffness was relatively low up to $400^{\circ} \mathrm{C}$; however, beyond $400^{\circ} \mathrm{C}$, a significant reduction was monitored in the ECC stiffness. As expected, with the increase of exposure temperature, the postpeak stress of the ECC specimens dropped faster, resulting in a smaller postpeak area under the curve. This behavior becomes more evident when the exposure temperature level reaches $800^{\circ} \mathrm{C}$ : ECC specimens failed soon after reaching their peak strength. This means that increasing the exposed temperature level tends to the ductile nature of ECC to brittle nature.

Figure 10 shows the influence of cooling regimes on the stress-strain curves. The strength and stiffness of specimens subjected to $400^{\circ} \mathrm{C}$ and quenching in water for 5 minutes were slight lower than the ones cooling in air, while the strength and stiffness of quenching specimens were much higher than the ones of the specimens cooling in air for $800^{\circ} \mathrm{C}$. As mentioned in Section 3.3, there is more new generated crystal in $800 \mathrm{~W}$ specimens than in $400 \mathrm{~W}$ specimens, which results in a more significant mechanical increase in $800 \mathrm{~W}$ specimens.

\section{Conclusions}

The objective of the present work was to investigate the influence of cooling regimes on the mechanical properties of ECC specimens subjected to elevated temperatures. ECC specimens were exposed to heating temperature up to $800^{\circ} \mathrm{C}$ and subjected to two different cooling regimes, that is, cooling in

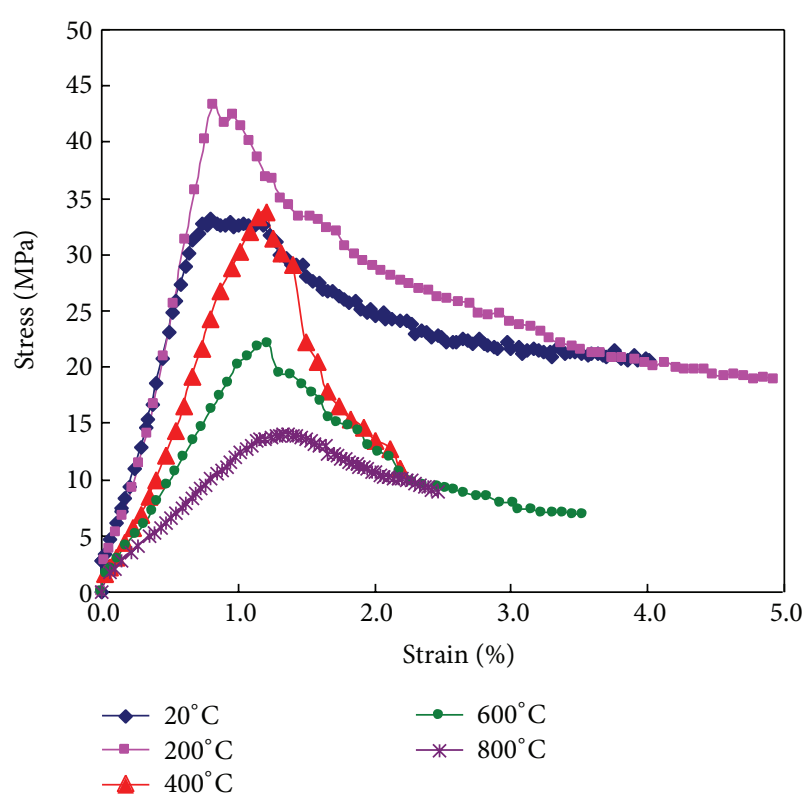

FIgURE 9: Post-fire specimens cooling in the air.

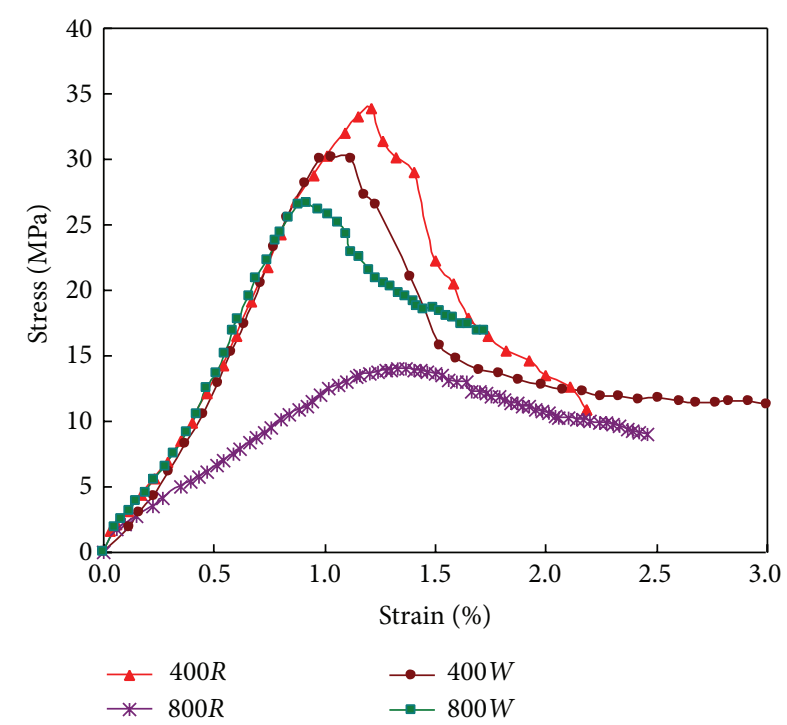

FIGURE 10: Stress-strain curve of specimens subjected to different cooling regimes.

air and quenching in water. The mechanical properties (compressive strength, stress-strain relationship, and stiffness) and microstructural properties (via SEM analyses) of ECC were studied at room temperature and postfire specimens. Based on this study, the following conclusions can be drawn.

(1) The color of ECC specimens changed from gray at $20^{\circ} \mathrm{C}$ to light yellow at $800^{\circ} \mathrm{C}$ and the specimens quenching in water turned to dark gray. Hairline cracks were monitored above $400^{\circ} \mathrm{C}$ and quenching in the water may help to heal the surface crack due to further hydration. 
(2) The mass loss increased with the increasing temperature of thermal exposure, a result mainly associated with the liberation of free and physically bound water. At higher temperatures of 600 and $800^{\circ} \mathrm{C}$, the weight change of ECC was caused by the dehydration of paste. During the heating treatment up to $400^{\circ} \mathrm{C}$, the weight of the melted fibers also had an influence on mass loss.

(3) The compressive strength can be classified in two stages of strength loss, $23-200^{\circ} \mathrm{C}$ and $200-800^{\circ} \mathrm{C}$. Temperatures no more than $200^{\circ} \mathrm{C}$ seem to help the strength increase. Beyond $200^{\circ} \mathrm{C}$, the compressive strength decreased monotonously with a drop of $61 \%$ at $800^{\circ} \mathrm{C}$. The cooling regime of quenching in water helped the strength and stiffness recovery.

(4) For temperature no more than $200^{\circ} \mathrm{C}$, ultimate stress increased with the increasing temperature, while, beyond $200^{\circ} \mathrm{C}$, ultimate stress decreased with the increasing temperatures. The slope decreases with the increase in exposure temperature up to $800^{\circ} \mathrm{C}$, indicating a reduction in the stiffness of the ECC. Increasing the exposed temperature level tends to the ductile nature of ECC to brittle nature.

\section{Conflict of Interests}

The authors declare that there is no conflict of interests regarding the publication of this paper.

\section{References}

[1] V. C. Li, "ECC-tailored composites through micromechanical modeling," in Proceedings of the Fiber Reinforced Concrete: Present and the Future Conference, N. Banthia, Ed., pp. 64-97, CSCE Press, Montreal, Canada, 1998.

[2] V. C. Li, "On engineered cementitious composites (ECC)-a review of the material and its applications," Advanced Concrete Technology, vol. 1, no. 3, pp. 215-230, 2003.

[3] M. Şahmaran and V. C. Li, "De-icing salt scaling resistance of mechanically loaded engineered cementitious composites," Cement and Concrete Research, vol. 37, no. 7, pp. 1035-1046, 2007.

[4] M. Sahmaran, M. Li, and V. C. Li, "Transport properties of engineered cementitious composites under chloride exposure," ACI Materials Journal, vol. 104, no. 6, pp. 604-611, 2007.

[5] F. Massazza, "Pozzolanic cements," Cement and Concrete Composites, vol. 15, no. 4, pp. 185-214, 1993.

[6] O. S. B. Al-Amoudi, M. Maslehuddin, M. Ibrahim, M. Shameem, and M. H. Al-Mehthel, "Performance of blended cement concretes prepared with constant workability," Cement and Concrete Composites, vol. 33, no. 1, pp. 90-102, 2011.

[7] E. Badogiannis and S. Tsivilis, "Exploitation of poor Greek kaolins: durability of metakaolin concrete," Cement and Concrete Composites, vol. 31, no. 2, pp. 128-133, 2009.

[8] R. J. Flatt, N. Roussel, and C. R. Cheeseman, "Concrete: an eco material that needs to be improved," Journal of the European Ceramic Society, vol. 32, pp. 2787-2798, 2012.

[9] M. Sahmaran, M. Lachemi, and V. C. Li, "Assessing mechanical properties and microstructure of fire-damaged engineered cementitious composites," ACI Materials Journal, vol. 107, no. 3, pp. 297-304, 2010.

[10] M. Şahmaran, E. Özbay, H. E. Yücel, M. Lachemi, and V. C. $\mathrm{Li}$, "Effect of fly ash and PVA fiber on microstructural damage and residual properties of engineered cementitious composites exposed to high temperatures," Journal of Materials in Civil Engineering, vol. 23, no. 12, pp. 1735-1745, 2011.

[11] X. Luo, W. Sun, and S. Y. N. Chan, "Effect of heating and cooling regimes on residual strength and microstructure of normal strength and high-performance concrete," Cement and Concrete Research, vol. 30, no. 3, pp. 379-383, 2000.

[12] G. Peng, S. Bian, Z. Guo, J. Zhao, X. Peng, and Y. Jiang, "Effect of thermal shock due to rapid cooling on residual mechanical properties of fiber concrete exposed to high temperatures," Construction and Building Materials, vol. 22, no. 5, pp. 948-955, 2008.

[13] V. C. Li, C. Wu, S. Wang, A. Ogawa, and T. Saito, "Interface tailoring for strain-hardening polyvinyl alcohol-engineered cementitious composite (PVA-ECC)," ACI Materials Journal, vol. 99, no. 5, pp. 463-472, 2002.

[14] H. F. W. Taylor, The Chemistry of Cements, Thomas Telford, London, UK, 1997.

[15] W. P. S. Dias, G. A. Khoury, and P. J. E. Sullivan, "Mechanical properties of hardened cement paste exposed to temperatures up to $700^{\circ} \mathrm{C}\left(1292^{\circ} \mathrm{F}\right), "$ ACI Materials Journal, vol. 87 , no. 2, pp. $160-166,1990$.

[16] G. A. Khoury, "Compressive strength of concrete at high temperatures: a reassessment," Magazine of Concrete Research, vol. 44, no. 161, pp. 291-309, 1992.

[17] T. T. C. Hsu, F. O. Slate, G. M. Sturman, and G. Winter, "Microcracking of plain concrete and the shape of the stressstrain curve," ACI Materials Journal, vol. 60, no. 2, pp. 209-224, 1963.

[18] G. A. Khoury, B. N. Grainger, and P. J. E. Sullivan, “Transient thermal strain of concrete: literature review, conditions within specimen and behavior of individual constituents," Magazine of Concrete Research, vol. 37, no. 132, pp. 131-144, 1985.

[19] G. A. Khoury, "Compressive strength of concrete at high temperatures: a reassessment," Magazine of Concrete Research, vol. 44, no. 161, pp. 291-309, 1992.

[20] B. Wu, X. Su, H. Li, and J. Yuan, "Effect of high temperature on residual mechanical properties of confined and unconfined high-strength concrete," ACI Materials Journal, vol. 99, no. 4, pp. 399-407, 2002.

[21] Z. P. Bažant and M. F. Kaplan, Concrete at High Temperatures: Material Properties and Mathematical Models, Longman Group, Essex, UK, 1996. 

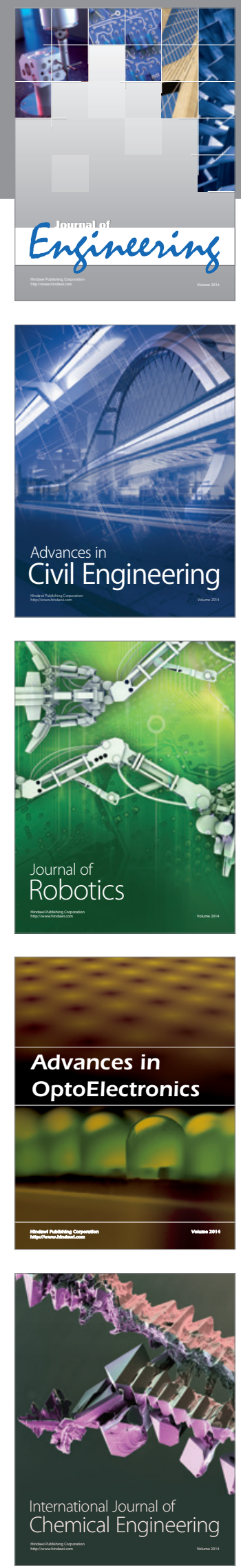

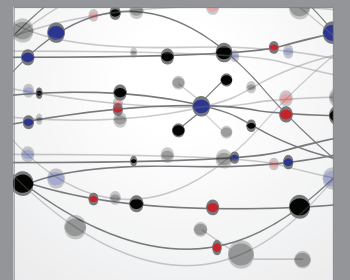

The Scientific World Journal
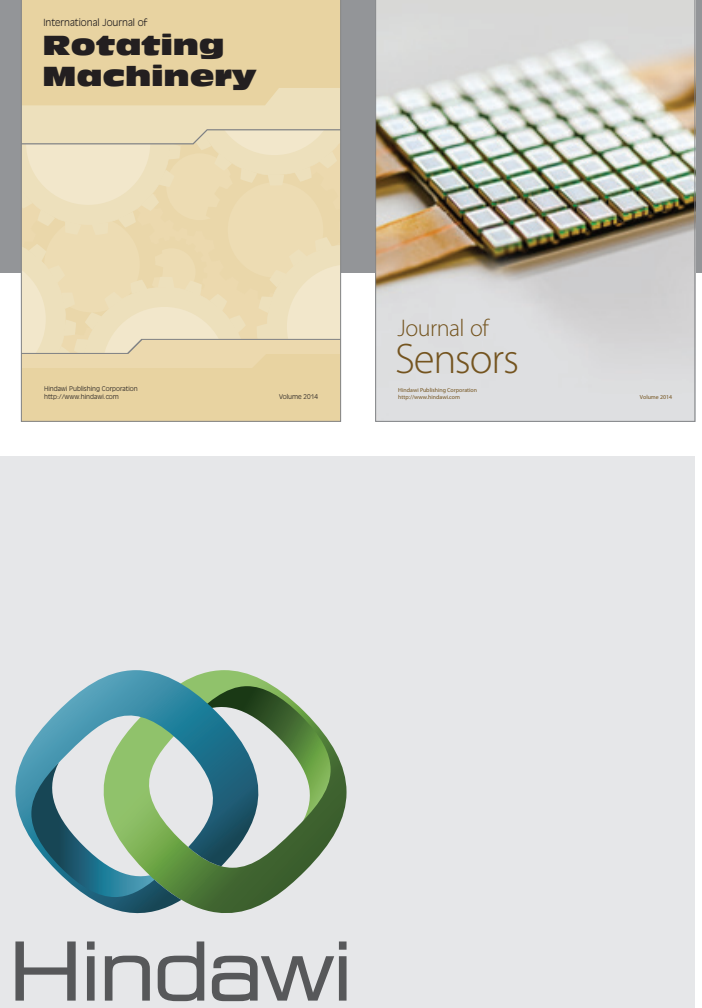

Submit your manuscripts at http://www.hindawi.com
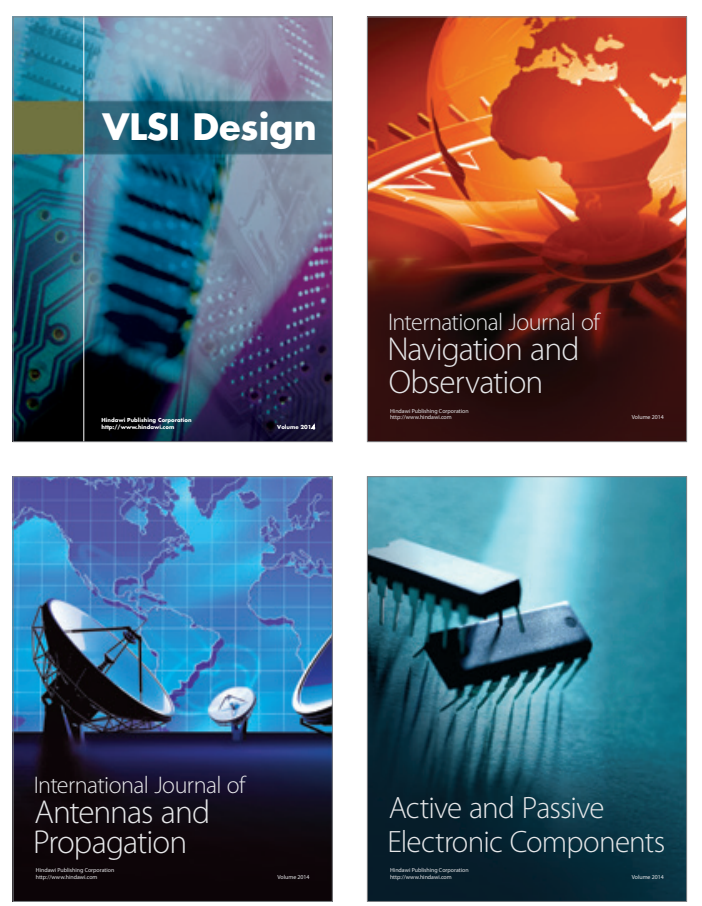
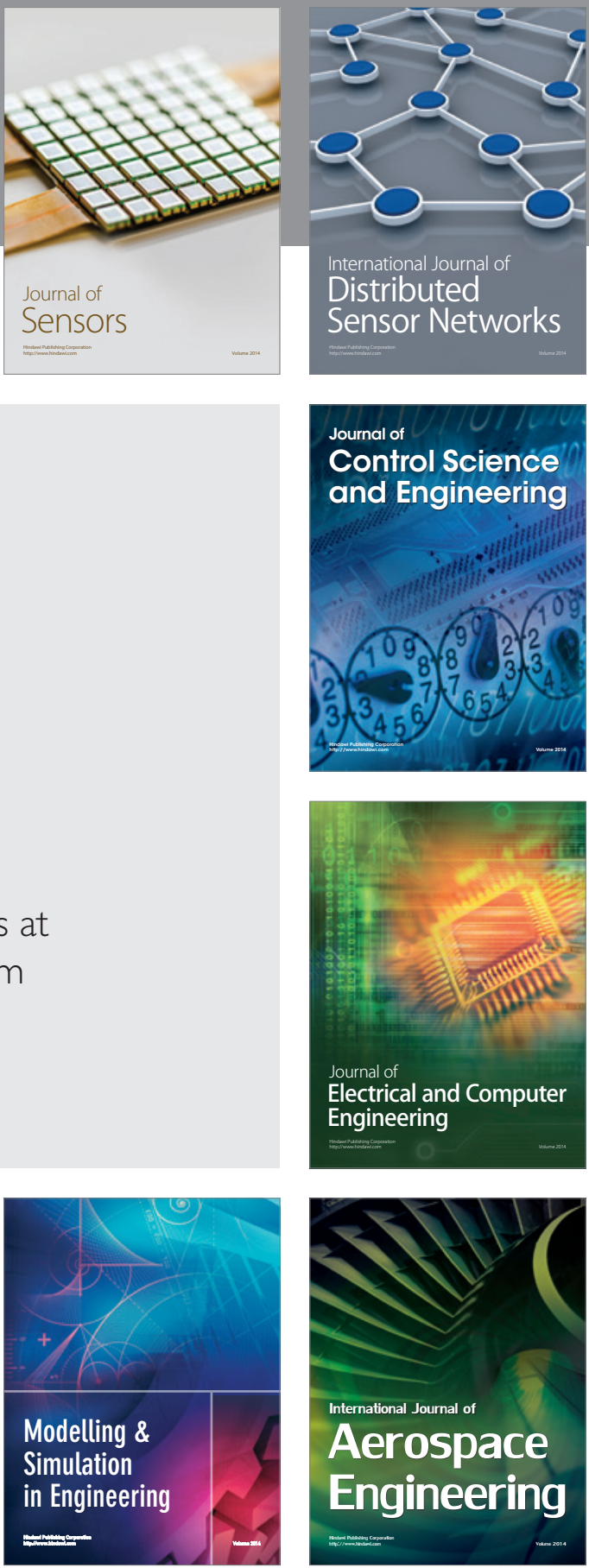

Journal of

Control Science

and Engineering
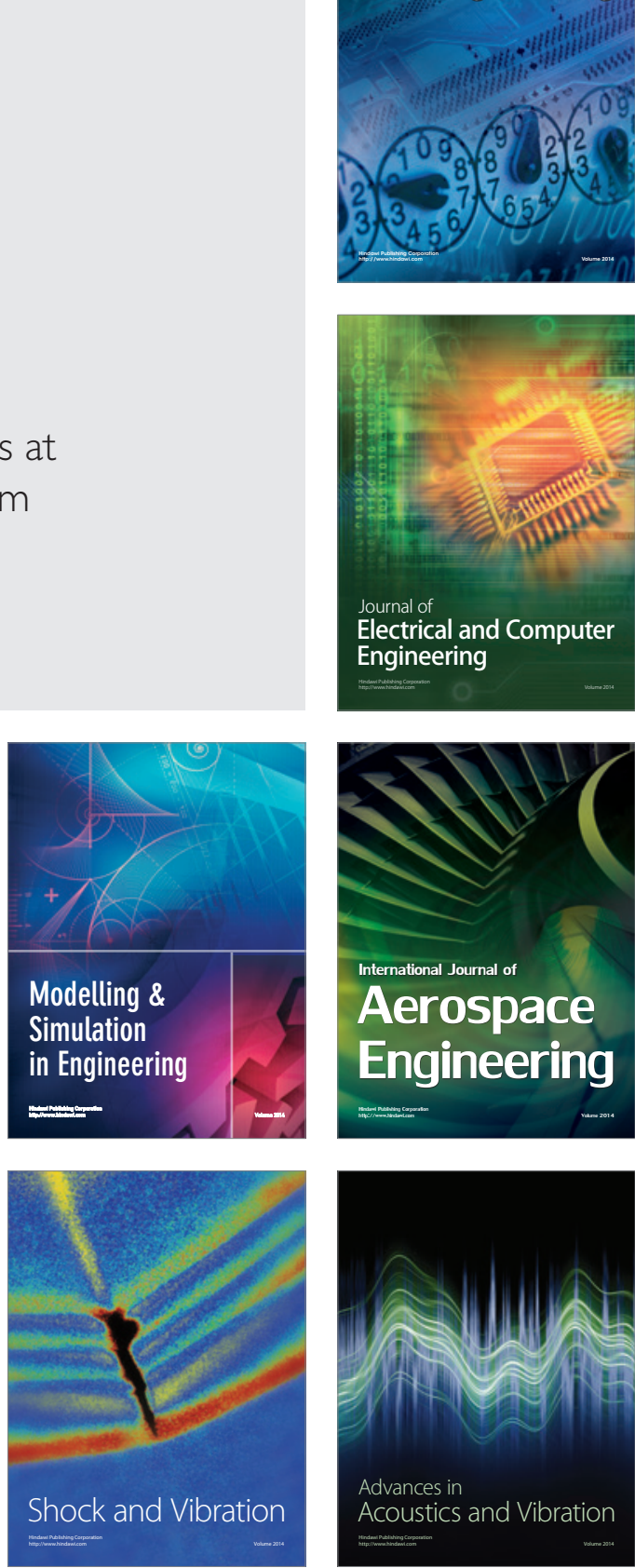